University of South Carolina

Scholar Commons

8-1997

\title{
Monetary Policy Preferences of Individual FOMC Members: A Content Analysis of the Memoranda of Discussion
}

Henry W. Chappell Jr.

University of South Carolina - Columbia, chappell@moore.sc.edu

Thomas M. Havrilesky

Rob Roy McGregor

Follow this and additional works at: https://scholarcommons.sc.edu/econ_facpub

Part of the Economics Commons

Publication Info

Review of Economics and Statistics, Volume 79, Issue 3, 1997, pages 454-460.

http://www.mitpressjournals.org/loi/rest

(C) 1997 by The MIT Press

This Article is brought to you by the Economics Department at Scholar Commons. It has been accepted for inclusion in Faculty Publications by an authorized administrator of Scholar Commons. For more information, please contact digres@mailbox.sc.edu. 


\title{
MONETARY POLICY PREFERENCES OF INDIVIDUAL FOMC MEMBERS: A CONTENT ANALYSIS OF THE MEMORANDA OF DISCUSSION
}

\author{
Henry W. Chappell, Jr., Thomas M. Havrilesky, and Rob Roy McGregor*
}

\begin{abstract}
The Memoranda of Discussion provide detailed records of Federal Open Market Committee (FOMC) meeting deliberations. Procedures are developed for coding the textual data in the Memoranda and assessing the reliability of those codings. The codings are then used in the estimation of parameters of individual FOMC members' reaction functions. Data from the 1970 to 1976 period are employed in the estimation. In the future, similar methods could be used to analyze newly released transcripts of FOMC meetings held after 1976.
\end{abstract}

$\mathrm{I}^{\mathrm{N}}$ N RECENT years empirical analyses of monetary policy making have increasingly focused on decisions made by individual members of the Federal Open Market Committee (FOMC). ${ }^{1}$ This focus is motivated by the recognition that members' individual decisions underlie the policy choices ultimately selected by the committee, and that members differ in their innate policy preferences, their political loyalties, and their responsiveness to external pressures. Most studies of individual FOMC members have examined records of votes on the monetary policy directives adopted by the committee at each of its meetings. While voting data are informative, some differences of opinion among FOMC members are not revealed by formal voting records. Once a monetary policy directive is put to a vote, there is a tendency for members to close ranks, vote approvingly, and present a united front to external parties. Given the paucity of dissents and the absence of other information that might reveal differing preferences, the ability of analysts to distinguish differing preferences across individuals or groups of individuals has been limited.

A possible way to learn more about the policy preferences of individual members of the FOMC is by studying the textual record of committee deliberations. This "narrative" approach has recently gained favor in studies of monetary policy making. However, most studies have not focused on the policy preferences of individual FOMC members. ${ }^{2}$

Received for publication January 5, 1994. Revision accepted for publication September 21, 1995.

* University of South Carolina, Duke University (deceased, 1995), and University of North Carolina at Charlotte, respectively.

We acknowledge the helpful comments of Raymond Lombra, Roger Waud, seminar participants at the University of North Carolina at Charlotte, the University of North Carolina at Chapel Hill, Rutgers University, and the University of South Carolina, and an anonymous referee. Research assistance was provided by Steven Nape, Matthew Neidell, Ann Poovey, David Ramsey, and Todd Vermilyea. Financial support has been provided by NSF grants SES-9122322 and SES-9121941 and by the University of North Carolina at Charlotte.

${ }^{1}$ Recent contributions include Chappell et al. (1993, 1995), Gildea (1990), Havrilesky (1995), Havrilesky and Gildea (1991), and Tootell (1991).

${ }^{2}$ Woolley (1984) made use of the FOMC's Memoranda of Discussion to provide a narrative of policy making for 1972, and Romer and Romer $(1989,1994)$ have used the Memoranda to help identify periods when the Fed intentionally shifted toward disinflationary or expansionary policy stances. Boschen and Mills (1995) use the Record of Policy Actions and the Memoranda to derive an indicator of monetary policy which they compare with indicators derived by other researchers from the same
Data available for such investigations have been limited. Until 1976, the FOMC recorded detailed minutes of meetings and published them after a five-year lag as Memoranda of Discussion. The Memoranda contained detailed descriptions of conversations that took place in meetings and linked (paraphrased) statements to specific individuals. In March 1976 the Fed announced that the Memoranda would be discontinued, and publication of detailed records ceased. It appeared that no detailed records of FOMC deliberations would exist for subsequent meetings. However, in October 1993 Federal Reserve Board Chairman Alan Greenspan revealed in congressional testimony that FOMC meetings held since 1976 had been audiotaped, that these tapes had been regularly transcribed, and that copies of the transcripts were being held within the Fed. The Fed subsequently agreed to release edited versions of these transcripts. ${ }^{3}$

In this paper we empirically investigate the policy preferences of individual FOMC members using data from the Memoranda of Discussion for the 1970-1976 period, beginning with Arthur Burns' appointment as chairman and ending with the cessation of the Memoranda. ${ }^{4}$ While our study adds detail to the existing descriptive history of monetary policy making in this period, our primary focus is on describing methods for reliably coding textual data from the Memoranda of Discussion for subsequent use in an econometric model of FOMC decision making. The literature on content analysis guides us in this effort. ${ }^{5}$ Since institutional arrangements for the making of monetary policy have not changed dramatically since the 1970s, these methods will have continuing applicability in the future, as newly released transcripts are made available.

In section I we describe the collection of our data and the subsequent assessment of their reliability. Section II describes our model of FOMC decision making and its empirical implementation. Section III presents the empirical results, and conclusions follow in section IV.

sources. The early work of Canterbery (1967) is the only previous study to code individuals' preferences on the directive based on comments recorded as the Memoranda. None of these studies, however, has incorporated data gleaned from the Memoranda into a model of FOMC decision making.

${ }^{3}$ By early 1995, the Fed had published transcripts for only three complete years.

${ }^{4}$ This sample period was chosen for several reasons. First, it is the most recent period for which the Memoranda are available. Second, the FOMC adhered closely to an interest-rate targeting procedure in this period. Our model has been developed for such an operating procedure. Third, in these years, the discussion of the committee was usually guided by the alternative policy scenarios presented by the Fed staff. This facilitates the coding of members' preferences.

${ }^{5}$ Discussions of the nature and techniques of content analysis are presented by Holsti (1969), Krippendorff (1980), and Weber (1985). Applications of content analysis in political science include Padgett (1982) and Mosley (1984). 


\section{A Content Analysis of the Memoranda of Discussion}

In each meeting of the FOMC, a monetary policy directive is selected by majority vote. Prior to voting on a policy directive, members customarily express their individual preferences in the "policy go-around." Discussion usually centers on members' views of policy scenarios that have been presented by the board's staff. After the discussion is completed, the chairman (or a member designated by the chairman) proposes a directive to be voted up or down, and the formal vote follows. In practice, directives are proposed only when majority support is assured.

Members can then cast either assenting or dissenting votes. It is customary to provide an explanation for dissents, which can almost always be characterized as "favoring ease" or "favoring tightness." 6 As we have noted, members who ultimately assent often give some indication of dissatisfaction with the adopted directive during the course of the meeting. In our coding of the Memoranda we will therefore distinguish three categories of assents: assents "leaning toward ease," assents "leaning toward tightness," and "pure assents." In our sample period there were 76 meetings of the FOMC, which produced 804 individual votes, excluding those of the chairman. ${ }^{7}$ Our coding task is to classify each of those votes into one of the five categories described above (dissents for ease or tightness, leans for ease or tightness, and pure assents). The remainder of this section describes our procedures for coding members' positions and assessing coding reliability.

Five features of our coding procedures are especially important for ensuring the quality of the resulting data series. First, students employed as coders were required to be knowledgeable in the field of monetary economics, but were not otherwise connected with the project. ${ }^{8}$ Second, coders were provided with identical written instructions describing how positions were to be recognized and coded. Third, all voting observations were independently coded by at least two individuals. When coding inconsistencies occurred, a third coder served as a "tie breaker." The tie breaker had access to the original source materials as well as the explanations for coding decisions provided by the first two coders. All coding inconsistencies were also reviewed by one of the authors, who provided an alternative coding which overruled the first tie breaker in some cases. Fourth, the reliability of the codings was assessed using measures of

\footnotetext{
${ }^{6}$ Our original sample included two observations where members dissented to indicate disapproval of the operating procedure rather than dissatisfaction with the adopted policy stance. These observations were omitted from our subsequent analysis.

${ }^{7}$ The chairman serves as an agenda setter and consensus builder. Further, no chairman has ever cast a dissenting vote. We believe that the voting behavior of the chairman is intrinsically different from that of other members and have excluded his votes from our analysis.

${ }^{8}$ We employed a total of five students as coders. One coder had completed an undergraduate degree with an economics major at Duke University, and the other four students were enrolled in master's or Ph.D. programs in economics at the University of North Carolina at Charlotte or the University of South Carolina.
}

consistency commonly employed in content analyses. Finally, reliability was further assessed by a sensitivity analysis of our statistical results. All of our estimations have been replicated for four sets of codings: (1) the codings provided by the first coder, (2) the codings provided by the second coder, (3) the composite coding provided by the first two coders with inconsistencies resolved by the student tie breaker, and (4) the composite codings with inconsistencies resolved by an author.

Basic source materials for coders were the Memorandum of Discussion and the Bluebook prepared by the board staff. The Bluebook describes alternative policy scenarios presented for the committee to consider in a meeting. For example, the staff might present three policy options, labeled $\mathrm{A}, \mathrm{B}$, and C, progressing from easiest to tightest. For each option, forecast ranges for money growth and the Federal funds rate are provided. Because members often couch their remarks in relation to these options, it is useful to have them available when coding.

The Memorandum of Discussion describes both the adopted directive and members' expressed preferences. In our coding scheme, leaning positions are defined relative to the adopted policy. Members are sometimes explicit about their desired funds rate ranges, which can be directly compared to the ranges adopted for the directive. When explicit information was available, coders were instructed to compare the midpoint of a member's desired funds rate range to the midpoint of the adopted range, and code leaning positions accordingly. For example, if an assenting member's suggested range has a midpoint of $6.0 \%$, but the adopted funds rate range midpoint is $6.5 \%$, then a "lean favoring ease" should be coded.

When members do not give explicit bounds for their desired funds rates, it is still possible to code leaning positions. A member might state a preference somewhere between alternatives A and B. If B is adopted and if A is the "easier" scenario, then a lean favoring ease should be coded. Similarly, a member might argue that the adopted policy $\mathrm{B}$ is acceptable, but note that errors in the direction of ease would be preferable to those in the opposite direction. Such statements would also be coded as "leans for ease." Detailed instructions given to coders are available from the authors upon request.

To have confidence in our subsequent analyses, we must determine whether the codings produced by our procedure are reliable. Reliability requires a reasonable degree of reproducibility; that is, the results produced from a content classification should be robust across multiple codings of the raw textual data. Our coding procedure produced two complete independent codings (i.e., codings before any tie-breaking) which serve as one basis for our assessment of reliability. We find agreement in the assigned category on $78.9 \%$ (634 out of 804) of the observations, with a correlation coefficient of 0.776 between the two codings. 
Although percent agreement and the correlation coefficient have often been reported in content analyses, neither is entirely adequate. Krippendorf (1980) has presented an alternative measure of consistency, known as Krippendorf's alpha, which has two desirable properties. First, in contrast to the percent agreement measure, it adjusts for those chance agreements which can occur even if codings are intrinsically unrelated. Second, it accounts for the ordinal character of the classifications. For our two independent codings, Krippendorff's alpha for ordinal data is 0.734 , which is interpreted to mean that observed agreement is $73.4 \%$ above chance. ${ }^{9}$ While there are no strict cut-off points for assessing an acceptable degree of reliability, values in the range of 0.67 to 0.80 are considered to be in a "gray area." In such cases, an assessment of the reliability of the codings hinges upon the robustness of results to the use of alternative sets of codings in the substantive analysis (Krippendorff (1980, p. 147)). We undertake such an assessment in section III.

While consistency of codings is an important issue, correctness of the codings is even more important. Matters of judgment clearly accounted for many of the discrepancies in our two original codings, but it is also clear that many discrepancies resulted from errors in the proper application of coding procedures. For example, in coding positions for the April 7, 1970, FOMC meeting, one coder incorrectly recorded the range for the Federal funds rate adopted by the committee. Since all individuals are coded relative to the adopted directive, such an error can affect the coding for each member present. In this particular case, nine coding discrepancies resulted from a single, easily identified error. An important function of our tie breaker is to detect and correct coding errors that have resulted in discrepancies.

Because our coders were instructed to explain their decisions, it is usually possible to distinguish errors from differing judgments. To help in the assessment of data reliability the author-coder categorized all discrepancies either as "coding errors" or as "coding ambiguities." Coding errors occur when an inconsistency results from factual errors or misapplications of coding procedures. Coding ambiguities occur when the original source materials are vague, contradictory, or inconclusive regarding an individual's position, or when coding instructions fail to cover special circumstances in a meeting. The author-coder classified 173 mismatching observations, finding a total of 122 errors and 51 ambiguities. ${ }^{10}$ Of these 173 discrepancies, 135 were resolved satisfactorily by the tie breaker, and 38 were reversed by the author-coder. Thus while the number of discrepancies was disappointing, many of them resulted

\footnotetext{
${ }^{9}$ If codings were assigned completely at random, one would expect a value of 0 for Krippendorff's alpha. In the case of complete agreement, Krippendorff's alpha would equal 1.0. The values of Krippendorff's alpha reported in the text were computed using a SAS macro provided in Kang et al. (1993).

${ }^{10}$ There were 170 discrepancies between coders 1 and 2 . In three other cases the author overruled coders 1 and 2 when they were in agreement. The author reviewed agreeing coders only when another discrepancy revealed an error with the potential to affect all codings in a meeting.
}

from minor correctable errors. We believe that our final coding corrects most such errors, and that relatively few positions are inherently difficult to code. In our final coding of members (i.e., with tie breaks resolved by the authorcoder), 17 observations (2.1\%) are coded as dissents for ease, $194(24.1 \%)$ are coded as leans toward ease, 346 (43.0\%) are coded as pure assents, 217 (27.0\%) are coded as leans toward tightness, and $30(3.8 \%)$ are coded as dissents for tightness.

\section{A Model of FOMC Decision Making}

This section summarizes our empirical model of FOMC decision making and methods for estimating its parameters. The model specifies policy preferences of individual FOMC members in the form of desired interest rate reaction functions and provides links between those preferences and ultimate policy outcomes. ${ }^{11} \mathrm{~A}$ key feature of the model is that parameters of individual FOMC members' monetary policy reaction functions are estimable, even though members' desired policy settings are unobserved.

The description of the model provided here is skeletal; extensive discussions of similar models and methods can be found in Chappell et al. (1993, 1995). In addition, a complete description of the model and estimation methods can be obtained in a working paper available from the authors upon request.

\section{A. Individuals' Reaction Functions}

We begin with equation (1), which specifies desired interest rate reaction functions for $N$ members of the FOMC:

$$
\begin{gathered}
r_{i t}^{*}=\alpha_{0}+\sum_{k=1}^{K} \alpha_{k} D_{k i t}+\sum_{j=1}^{J} \beta_{j} X_{j t}+e_{i t} \\
i=1, \ldots, N ; t=1, \ldots, T
\end{gathered}
$$

The dependent variable $r_{i t}^{*}$ is member $i$ 's desired Federal funds rate for the intermeeting period following meeting $t$. Members' desired funds rates are not directly observable. ${ }^{12}$ The reaction functions include two sets of independent variables, $X_{j t}, j=1, \ldots, J$, and $D_{k i t}, k=1, \ldots, K$. Included among the $X_{j t}$ are macroeconomic indicators of concern to the Fed, for example, forecasts of inflation or unemployment. These variables are assumed to vary over time but not across members. The variables included among the $D_{k i t}$ vary across both members and time. In the present analysis, these are dummy variables indicating specific individuals serving

\footnotetext{
${ }^{11}$ Monetary policy reaction functions empirically link a policy instrument, e.g., the Federal funds rate, to prevailing macroeconomic conditions. A reaction function conveniently describes the implicit policy rule followed by the central bank. Khoury (1990) provides a recent review of the reaction function literature.

${ }^{12}$ Although the Memoranda sometimes indicate individual members' desired ranges for the Federal funds rate, this is not routinely the case.
} 
on the FOMC..$^{13}$ The inclusion of these dummy variables permits each committee member to have a different reaction function intercept. ${ }^{14}$ In addition, error terms for the reaction functions (1) are assumed to be independently normally distributed with mean zero and variance $\sigma^{2}$.

\section{B. FOMC Decision Making}

In order to estimate the parameters of equation (1) with the available data, some additional assumptions about the policy-making process are required. These assumptions are described below.

1. The policy directives adopted by the FOMC effectively set a target value for the Federal funds rate. During the 1970s the FOMC adopted targets for both money growth and the funds rate. However, because the range of permitted funds rates was usually narrow, the operating procedure is best viewed as funds rate targeting. ${ }^{15}$

2. The adopted funds rate depends on the desired rates of committee members. We specify that the funds rate $r_{t}$ adopted by the committee is a weighted average of the chairman's desired rate and the mean of the desired rates of all other members. The chairman's voting weight $\gamma$ is an estimable parameter of the model.

3. The funds rate adopted by the committee is observed as the average rate prevailing in the postmeeting period. This assumption provides a needed link between individuals' desired policies, which are not observed, and the postmeeting funds rate, which is observed.

4. Conflicts resulting in either formal dissents or internal expressions of disagreement within FOMC meetings are generated by differences in underlying policy preferences. We model the behavior of individual members by assuming that differences between an individual's desired funds rate and the funds rate adopted by the committee trigger both dissents and leaning positions. Specifically, if a member prefers a funds rate lower than that adopted by the committee, and if the difference in rates is sufficiently large (i.e., greater than $\lambda_{1}$ ), the member will "lean" toward ease. If the difference is even larger (i.e., greater than $\lambda_{2}$ ), the member will dissent favoring ease. Similarly, dissents or leans toward tightness are generated when an individual prefers a higher funds rate than that specified in the proposed directive. The threshold parameters $\lambda_{1}$ and $\lambda_{2}$ are also estimable.

\footnotetext{
${ }^{13}$ Over an extended sample period, many specific individuals will occupy the $N$ positions on the committee (when there are no vacancies or absences, $N=11$ ). In our notational scheme, member $i$ refers to the arbitrarily assigned position number of a member, i.e., $i \in\{1, \ldots, N\}$. Member $i$ need not be the same specific individual over time.

${ }^{14}$ The model could be generalized to permit other reaction function parameters to vary across members. However, it is doubtful that such distinctions can be assessed reliably with the limited data available.

${ }^{15}$ See Goodfriend (1991) for a supporting view.
}

\section{Empirical Specification}

In our empirical model the variables $D_{k i t}$ in the reaction function (1) are dummy variables for 30 individual members of the FOMC (excluding the chairman) who voted five or more times on the monetary policy directive during the 1970-1976 period. ${ }^{16}$ The remaining members accounted for a total of just six votes and are collectively represented in the intercept $\alpha_{0}$.

Economic target variables included among the $X_{j t}$ in the reaction functions are identical to those used in Chappell et al. $(1993,1995)$ and are typical of other reaction function studies. We include the lagged Federal funds rate $r_{t-1}$, calculated as the average Federal funds rate between meetings $t-1$ and $t$, to account for inertia in the movement of interest rates. Lagged money growth $\dot{M} 1_{t-1}$, calculated as the growth rate of $M 1$ over the two months preceding the meeting, is also included. The remaining economic variables are three-month-ahead forecasts of the percentage rate of change in the consumer price index $\dot{P}_{t}$, the unemployment rate $U_{t}$, and the growth rate of industrial production $I P_{t} .{ }^{17}$

Although our general model treats the chairman's voting weight $\gamma$ as an estimable parameter, in practice we have found that its estimates are often imprecise and implausible in magnitude. ${ }^{18}$ In our subsequent empirical work we have therefore estimated the model while imposing alternative plausible values $(0.25,0.50,0.75)$ for $\gamma .{ }^{19}$

\section{Results}

Table 1 presents estimates of the key model parameters. The coefficients of economic variables in the reaction functions were obtained from ordinary least-squares (OLS) estimation of a reduced-form equation derived from our model to explain the postmeeting Federal funds rate. With the exception of the inflation rate, signs of the coefficients of economic variables in the reaction function are consistent with the hypothesis that the Fed "leans against the wind" in setting its policy instrument. However, only the lagged funds

\footnotetext{
${ }^{16}$ The choice of five votes as the criterion for including a dummy variable for a specific individual is somewhat arbitrary. However, it is difficult to obtain reliable estimates for individuals who do not vote often. The criterion of at least five votes seems to offer a reasonably inclusive and tractable solution.

${ }^{17}$ The forecasts are predicted values from "rolling" regression equations, explaining each of the target variables. For details, see Chappell et al. (1993).

${ }^{18}$ Our data provide evidence on $\gamma$ which is, at best, indirect. The weight of the chairman is inferred from evidence on how responsive a given member is to variations in the composition of the remainder of the committee. For example, if members are very responsive to variations in the composition of the committee, it is inferred that the other members have a large impact on the adopted directive, and that the impact of the chairman must then be relatively small. In the absence of more direct evidence, it is not surprising that $\gamma$ is not satisfactorily estimated.

${ }^{19}$ In Chappell et al. (1993) $\gamma$ was estimated to be about 0.21. Alternative estimates were obtained by Havrilesky and Gildea (1994), who surveyed monetary policy scholars to solicit their subjective estimates of $\gamma$. Respondents typically reported $\gamma$ values in the 0.6 to 0.8 range. When specifically asked for a $\gamma$ value for Burns, the mean response was 0.73 . We are not aware of any other quantitative assessments of the chairman's power.
} 
Table 1.-Monetary Policy Reaction Functions with Individual Intercepts: Ordered Probit Estimates

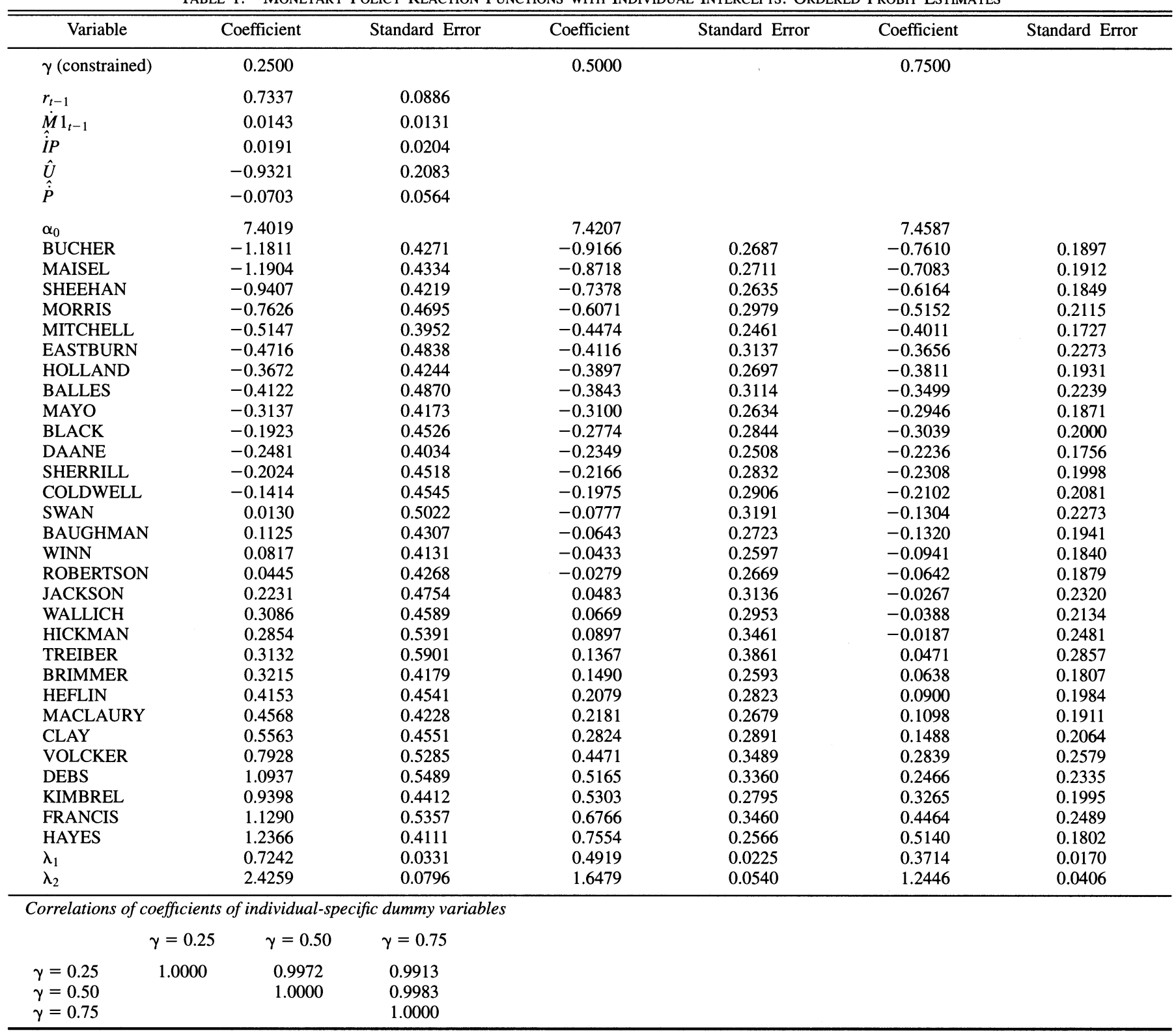

rate and the unemployment rate are significantly different from zero at the 0.05 level.

The parameters describing differences across individuals have been obtained from the estimation of a reduced-form five-category ordered probit model, again derived from our behavioral model, explaining members' coded policy positions. All of the estimates presented in table 1 employ our final set of codings in which decisions regarding discrepancies were reviewed by an author-coder. The results provide evidence of considerable diversity across members, despite the infrequency of formal dissents. We initially focus on the estimation in which the chairman's weight $\gamma$ is set equal to 0.50 . In table 1 , members are listed by intercepts in ascending order (i.e., from easy to tight) in the center column, corresponding to $\gamma=0.50$. Extremes are repre- sented by Governor Jeffrey Bucher and New York Federal Reserve Bank president Alfred Hayes. Other things held equal, desired funds rates for Hayes and Bucher differ by 1.67 percentage points, with Bucher preferring the easier stance. Statistically significant differences between members can be detected in many cases. For example, Wald tests (not reported) reveal that Bucher's intercept is significantly lower (at the 0.01 level or better) than those of 24 other members. Governor J. L. Robertson, whose intercept ranks him near the median for the group, has an intercept significantly higher than five others and significantly lower than three others.

When alternative values are imposed for $\gamma$, the chairman's voting weight, results are similar in most respects. However, the variance of the reduced-form probit model error term 
Table 2-Sensitivity Analysis: Coefficient Estimates ObTained FROM ALTERNATIVE CODINGS

\begin{tabular}{|c|c|c|c|c|}
\hline Variable & Coder 1 & Coder 2 & Tie Broken & Overruled \\
\hline$\gamma($ constrained) & 0.5000 & 0.5000 & 0.5000 & 0.5000 \\
\hline$\alpha_{0}$ & 7.3331 & 7.4380 & 7.4232 & 7.4207 \\
\hline BUCHER & -0.6326 & -0.9198 & -0.9478 & -0.9165 \\
\hline MAISEL & -0.7265 & -0.7837 & -0.9267 & -0.8718 \\
\hline SHEEHAN & -0.5887 & -0.7006 & -0.7427 & -0.7378 \\
\hline MORRIS & -0.4096 & -0.5705 & -0.5792 & -0.6071 \\
\hline MITCHELL & -0.2589 & -0.3021 & -0.3771 & -0.4474 \\
\hline EASTBURN & -0.2604 & -0.4474 & -0.5020 & -0.4116 \\
\hline HOLLAND & -0.0595 & -0.3554 & -0.3876 & -0.3897 \\
\hline BALLES & -0.1616 & -0.3234 & -0.3834 & -0.3843 \\
\hline MAYO & -0.2247 & -0.2494 & -0.4169 & -0.3100 \\
\hline BLACK & -0.0478 & -0.2790 & -0.2879 & -0.2774 \\
\hline DAANE & 0.0541 & -0.2384 & -0.2909 & -0.2349 \\
\hline SHERRILL & -0.0326 & -0.2860 & -0.2410 & -0.2166 \\
\hline COLDWELL & -0.0894 & -0.1933 & -0.2014 & -0.1975 \\
\hline SWAN & 0.1169 & -0.0755 & -0.0916 & -0.0777 \\
\hline BAUGHMAN & 0.0994 & -0.1310 & -0.0526 & -0.0643 \\
\hline WINN & 0.2178 & -0.0507 & -0.0582 & -0.0433 \\
\hline ROBERTSON & 0.1452 & -0.1566 & -0.0195 & -0.0279 \\
\hline JACKSON & 0.1969 & 0.1944 & 0.1868 & 0.0483 \\
\hline WALLICH & 0.2655 & 0.0731 & 0.0663 & 0.0669 \\
\hline HICKMAN & 0.2669 & -0.0261 & -0.0378 & 0.0897 \\
\hline TREIBER & 0.1355 & 0.1170 & 0.3009 & 0.1367 \\
\hline BRIMMER & 0.2630 & 0.1311 & 0.1511 & 0.1490 \\
\hline HEFLIN & 0.2168 & 0.2102 & 0.1923 & 0.2079 \\
\hline MACLAURY & 0.3210 & 0.2193 & 0.1269 & 0.2181 \\
\hline CLAY & 0.4434 & 0.3229 & 0.2677 & 0.2824 \\
\hline VOLCKER & 0.3308 & 0.0938 & 0.3467 & 0.4471 \\
\hline DEBS & 0.7065 & 0.4919 & 0.5157 & 0.5165 \\
\hline KIMBREL & 0.5639 & 0.5262 & 0.5537 & 0.5303 \\
\hline FRANCIS & 0.9187 & 0.7088 & 0.6763 & 0.6766 \\
\hline HAYES & 0.8677 & 0.7256 & 0.7633 & 0.7554 \\
\hline$\lambda_{1}$ & 0.4985 & 0.4865 & 0.4871 & 0.4919 \\
\hline$\lambda_{2}$ & 1.6234 & 1.6338 & 1.6558 & 1.6479 \\
\hline \multicolumn{5}{|c|}{ Correlations of coefficients of individual-specific dummy variables } \\
\hline & Coder 1 & Coder 2 & Tie Broken & Overruled \\
\hline Coder 1 & 1.0000 & 0.9715 & 0.9687 & 0.9773 \\
\hline Coder 2 & & 1.0000 & 0.9829 & 0.9787 \\
\hline Tie broken & & & 1.0000 & 0.9900 \\
\hline Overruled & & & & 1.0000 \\
\hline
\end{tabular}

depends on $\gamma$, and this affects the scaling of other parameters. For example, as $\gamma$ varies from 0.25 to 0.75 , the dissent threshold parameter $\lambda_{2}$ varies from 2.40 to 1.24 . Nevertheless, inferences about members' relative preferences for ease versus tightness are quite robust. Pairwise correlations for the three sets of coefficients in table 1 are all above 0.99 .

We now return to the issue of reliability of our qualitative data. A key attribute of coding reliability is that independent codings should produce similar substantive conclusions. Table 2 addresses this concern. In this table we report estimates based on four sets of codings: (1) coder 1, (2) coder 2, (3) coders 1 and 2 with discrepancies resolved by the tie breaker, and (4) coders 1,2, and the tie breaker, with overrules provided by an author-coder. In each case $\gamma$ has been set equal to 0.50 . Results across the four columns are remarkably similar. Pairwise correlations of the coefficients on individual-specific dummy variables are above 0.96 in all cases, and rankings of members are nearly identical. Thus despite a number of discrepancies across coders, including many correctable errors, our findings appear to be robust.

From a methodological perspective we are also interested in how the availability of data on "leaning" positions improves our ability to accurately characterize members' preferences. To make such an assessment, we recoded all leaning positions as pure assents, thus discarding the information obtained from the Memoranda. We then employed a three-category ordered probit model to estimate the parameters of the original model (excepting $\lambda_{1}$, the threshold for leans). Results (not reported) showed that coefficient standard errors are typically inflated by about $50 \%$ in the results based on the three-category probit model. Tests of differences between members also revealed fewer significant differences. For example, Bucher differed significantly from only 21 other members (at the 0.01 level), whereas Robertson differed significantly from just four. Evidently, data from the Memoranda do permit more refined distinctions to be made across members.

Members' intercept rankings were generally similar in the three-category and five-category estimations. The correlation coefficient for the two sets of estimates was 0.86, indicating considerable consistency between voting behavior and coded leans, yet not so much consistency that the data on leans could be considered redundant. For example, estimates from the three-category probit model suggested that Henry Wallich was one of the more ease-oriented FOMC members (his only dissent in 25 votes was in favor of ease), whereas estimates making use of the five-category classification suggested the reverse (he leaned for tightness 12 times and for ease only five times). In the years following 1976 , Wallich consistently favored tighter policies than most of his colleagues, a behavioral pattern which is predictable based on our estimates using data from the Memoranda, but not predictable from his prior voting record.

\section{Conclusions}

Dissent voting data have previously been employed to test a variety of propositions about the behavior of different groups of FOMC members. In this paper we have introduced a new set of data on individuals' monetary policy preferences that have been extracted from the FOMC's Memoranda of Discussion. We find that use of the new data permits notably greater precision in estimating parameters of individual FOMC members' reaction functions. We also find that independent codings of the members' leaning positions revealed in the Memoranda of Discussion are able to capture aspects of individuals' policy preferences which are not evident in voting data alone. Specifically, estimates of members' reaction function parameters are robust across data produced by independent codings of the Memoranda, but in some cases, the estimates are notably different from those obtained when only voting data are used.

In early 1995 the FOMC voted to continue providing edited transcripts of its meetings to the public (after a five-year waiting period), assuring researchers of an ongoing 
source of data describing policy preferences of individual committee members. Our analysis shows that a careful coding of these records should be valuable in future investigations of FOMC decision making.

\section{REFERENCES}

Boschen, John F., and Leonard O. Mills, "The Relation between Narrative and Money Market Indicators of Monetary Policy," Economic Inquiry 33 (1995), 24-44.

Canterbery, E. Ray, "A New Look at Federal Open Market Voting," Western Economic Journal 6 (1967), 25-38.

Chappell, Henry W., Jr., Thomas M. Havrilesky, and Rob Roy McGregor, "Partisan Monetary Policies: Presidential Influence through the Power of Appointment," Quarterly Journal of Economics 108 (1993), 185-218.

"Policymakers, Institutions, and Central Bank Decisions," Journal of Economics and Business 47 (1995), 113-136.

Gildea, John, "Explaining FOMC Members' Votes," in Thomas Mayer (ed.), The Political Economy of American Monetary Policy (New York: Cambridge University Press, 1990).

Goodfriend, Marvin, "Interest Rates and the Conduct of Monetary Policy," Carnegie-Rochester Conference Series on Public Policy 34 (1991), 7-30.

Havrilesky, Thomas, The Pressures on American Monetary Policy, 2nd. ed. (Boston: Kluwer Academic Publishers, 1995).

Havrilesky, Thomas, and John Gildea, "The Policy Preferences of FOMC Members as Revealed by Dissenting Votes," Journal of Money, Credit, and Banking 23 (1991), 130-138.
"The Relative Importance of the Chairman in FOMC Deliberations," working paper (1994).

Holsti, Ole R., Content Analysis for the Social Sciences and Humanities (Reading, MA: Addison-Wesley, 1969).

Kang, Namjun, Ali Kara, H. A. Laskey, and F. B. Seaton, "A SAS Macro for Calculating Intercoder Agreement in Content Analysis," Journal of Advertising 22 (1993), 17-28.

Khoury, Salwa, "The Federal Reserve Reaction Function: A Specification Search," in Thomas Mayer (ed.), The Political Economy of American Monetary Policy (New York: Cambridge University Press, 1990)

Krippendorff, Klaus, Content Analysis: An Introduction to Its Methodology (Beverly Hills, CA: Sage Publications, 1980).

Mosley, Paul, " 'Popularity Functions and the Role of the Media: A Pilot Study of the Popular Press," British Journal of Political Science 14 (1984), 117-129.

Padgett, George E., "The Voting Record of Justice Stewart on First Amendment Cases," Journalism Quarterly 59 (1982), 554-559.

Romer, Christina, and David Romer, "Does Monetary Policy Matter? A New Test in the Spirit of Friedman and Schwartz," NBER Macroeconomics Annual 4 (1989), 121-170.

"What Ends Recessions," NBER Macroeconomics Annual 9 (1994), 13-57.

Tootell, Geoffrey M. B., "Are District Presidents More Conservative than Board Governors?," New England Economic Review (Sept./Oct. 1991), 3-12.

Weber, Robert Philip, Basic Content Analysis (Beverly Hills, CA: Sage Publications, 1985).

Woolley, John, Monetary Politics (New York: Cambridge University Press, 1984). 